slowing dramatically from 2006 to 2008. JoinPoint regression analysis of different age groups demonstrates that the slower rate of decline from 2006 may be due to stubbornly high numbers of deaths in the 35-44 age group. Lastly the National figures on mortality from $\mathrm{CHD}$ are shown to be misleading as many people are still dying from CHD just when they have crossed the 75-year old exclusion criteria; as a result a delay in mortality is presented as prevention of mortality from CHD.

Discussion There is a danger that previous successes are being offset by high rates in the younger cohorts, and that the overall trend may be eventually be reversed. There is still work to be done in reducing risk factors and also applying treatments that have had a proven positive impact (such as revascularisation) more effectively. Statistically significant changes in declining CHD mortality rates.

Future work This 10000 word report formed the basis of a funding application to the British Heart Foundation for a follow-up to the United Kingdom Heart Attack Study.

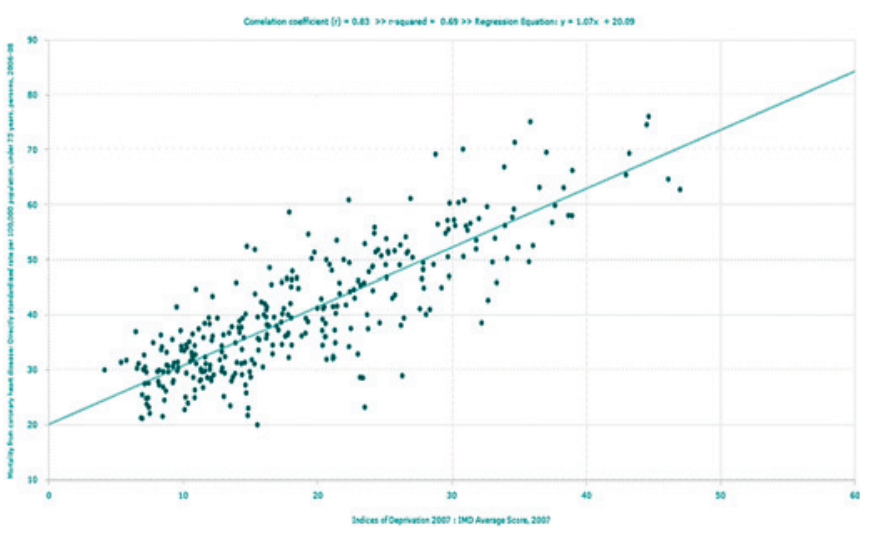

Abstract 17 Figure 2

\section{PATIENTS PRESENTING WITH ANAEMIA UNDERGOING PRIMARY PCI APPEAR AT SIGNIFICANTLY HIGHER RISK OF AN ADVERSE OUTCOME}

doi:10.1136/heartjnl-2011-300198.18

K R Rathod, D A Jones, B Rathod, A Graham, E Sammut, S Gallagher, J Behar, A K Jain, C Knight, A Mathur, A Wragg, R Amersey. Barts and the London NHS trust, London, UK

Background Previous studies have demonstrated a relationship between pre-existing anaemia and inpatient mortality after percutaneous coronary intervention (PCI). There is limited data looking at the impact of baseline Haemoglobin and long term outcome after primary PCI.

Methods Clinical information was analysed from a prospective database on 2357 STEMI patients who underwent Primary PCI between January 2004 and May 2010 at a London centre. Information was entered at the time of procedure and outcome assessed by all-cause mortality information provided by the Office of National Statistics via the BCIS/CCAD national audit. Anaemia was defined according to WHO definition of $\mathrm{Hb}$ greater than or equal to $12 \mathrm{~g} / \mathrm{dl}$ for females and $13 \mathrm{~g} / \mathrm{dl}$ for males.

Results $471(20 \%)$ patients were anaemic at presentation. The anaemic cohort, were older (72.2 vs 62.4, p<0.0001), had higher incidence of diabetes ( $27 \%$ vs $15 \%, \mathrm{p}<0.0001)$, hypertension (42 vs $35 \%, p=0.01$ ), hypercholesterolaemia (40 vs $30 \%, p=0.007$ ), previous PCI ( 13 vs $7 \%, p=0.01)$, and previous MI ( $23 \%$ vs $12 \%$, $p<0.0001)$. There were similar incidences of three-vessel disease and cardiogenic shock. Over a 3-year follow-up period there was significantly higher all cause mortality in the anaemic group compared to the normal Hb group (20.4\% vs $13.5 \%$, $\mathrm{p}<0.0001)$. See Abstract 18 figure 1. After adjusting for comorbidities, anaemia remained an independent predictor of long-term adverse outcome $(\mathrm{OR}=2.4,95 \%$ $\mathrm{CI}=1.1$ to $3.7, \mathrm{p}<0.001)$. Patients with baseline anaemia who received a blood transfusion were significantly more likely to suffer an adverse outcome than those that did not receive a transfusion (21\% vs 6\%, p <0.0001).

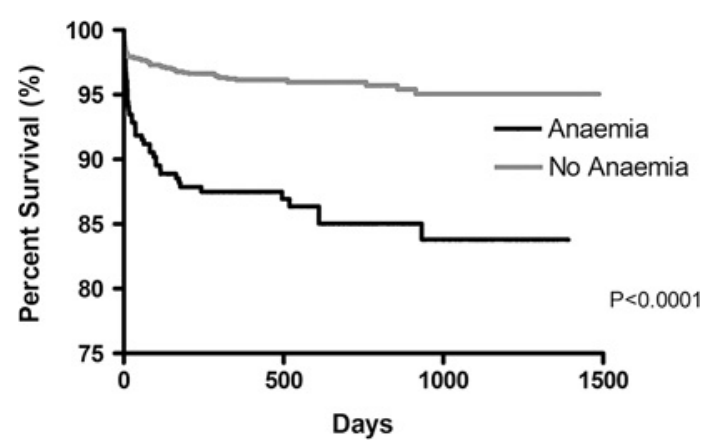

Abstract 18 Figure 1 All cause mortality after PCI for STEMI.

Conclusion Patients presenting with anaemia undergoing primary PCI appear at significantly higher risk of an adverse outcome. This risk increases further in population receiving $\mathrm{RBC}$ transfusions during index hospitalisation.

\section{TREATMENT OF MULTIVESSEL CORONARY ARTERY DISEASE IN PRIMARY PCI FOR ST ELEVATION MYOCARDIAL INFARCTION: CULPRIT ONLY REVASCULARISATION IS ASSOCIATED WITH HIGHER MACE RATES}

doi:10.1136/heartjnl-2011-300198.19

K S Rathod, L A McGill, E Sammut, V S Rathod, D A Jones, R Weerackody, A Jain, C Knight, A Mathur, A Wragg. London Chest Hospital NHS Trust, London, UK

Background Multi-vessel disease occurs in $40 \%-65 \%$ of patients undergoing Primary PCI for STEMI and is associated with adverse prognosis. Contemporary guidelines recommend treating the infarct related artery alone (culprit) during the urgent procedure. There is limited data comparing outcomes of complete with infarct-related artery (IRA)-only revascularisation in primary PCI for STEMI with few studies including the option of later date elective procedures for the other lesions (staged revascularisation). We therefore sought to clarify the outcome of patients with multi-vessel disease undergoing primary PCI dependent on management strategy.

Methods Clinical information was analysed from a prospective data base on 2131 STEMI patients who underwent Primary PCI between January 2004 and May 2010 at a London centre. Patients with previous CABG were excluded. Information was entered at the time of procedure and outcome assessed by all-cause mortality information provided by the Office of National Statistics via the BCIS/ CCAD national audit. Patients were split into three different treatment groups: culprit vessel angioplasty-only (COR group); staged revascularisation (SR group) and simultaneous treatment of non-IRA (CR group). The primary end point used was major adverse cardiac events (MACE), defined as death, myocardial infarction (MI), stroke and target vessel revascularisation (TVR).

Results There were 963 (45\%) consecutive patients with STEMI and multivessel $\mathrm{CAD}$ undergoing primary angioplasty. There were similar baseline characteristics between the 3 groups, aside from cardiogenic shock, which was significantly higher in the complete revascularisation group. See Abstract 19 table 1. At 30-days of follow-up, 23/263 (9\%) patients in the CR group experienced at least one major adverse cardiac event (MACE), $1(1 \%)$ in the SR group and $35(5 \%)$ in the COR group, $\mathrm{p}=0.01$. This trend continued 
up to 1-year of follow-up with the lowest rates of events in the SR group. However after 3 years MACE rates are significantly increased in the COR group (24\%) but were similar in the CR (18\%) and SR (17\%) groups. See Abstract figure 1. MACE rates were driven mainly by death in the CR with high rates of TVR in the COR and SR groups. See Abstract figure 2.

\section{Abstract 19 Table 1}

\begin{tabular}{lcccc}
\hline & COR N=638 & SR N=100 & CR N=263 & Significance \\
\hline Age & 64.77 & 61.46 & 64.32 & 0.144 \\
Gender (female) & $156(23.7 \%)$ & $13(13.0 \%)$ & $74(27.9 \%)$ & 0.0114 \\
Ethnicity (Caucasian) & $441(67.0 \%)$ & $79(79.0 \%)$ & $185(69.8 \%)$ & 0.0511 \\
Previous MI & $109(16.6 \%)$ & $11(11.0 \%)$ & $36(13.6 \%)$ & 0.2414 \\
Previous CABG & $15(2.3 \%)$ & $2(2.0 \%)$ & $3(1.1 \%)$ & 0.5231 \\
Previous PCI & $83(12.6 \%)$ & $5(5.0 \%)$ & $23(8.7 \%)$ & 0.031 \\
Diabetes Mellitus & $129(19.6 \%)$ & $16(16.0 \%)$ & $55(20.8 \%)$ & 0.5932 \\
Hypertension & $312(48.1 \%)$ & $40(40.0 \%)$ & $91(41.2 \%)$ & 0.1205 \\
Hypercholestrolaemia & $269(41.5 \%)$ & $37(37.0 \%)$ & $92(41.6 \%)$ & 0.7751 \\
GPIlb/Illa Inhibitor & $572(87.7 \%)$ & $93(93.0 \%)$ & $231(89.5 \%)$ & 0.1724 \\
Cardiogenic Shock & $29(4.7 \%)$ & $2(2.0 \%)$ & $31(12.26 \%)$ & $\mathrm{p}<0.0001$ \\
\hline
\end{tabular}

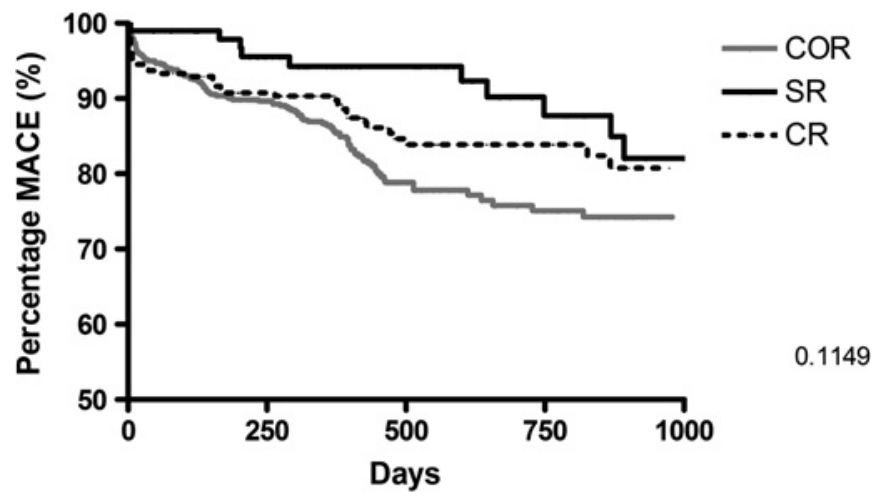

\begin{tabular}{llllll}
\multicolumn{2}{c}{ Numbers at Risk } & & & & \\
& $\mathbf{0}$ & $\mathbf{2 5 0}$ & $\mathbf{5 0 0}$ & $\mathbf{1 0 0 0}$ & $\mathbf{1 5 0 0}$ \\
COR & 656 & 465 & 160 & 101 & 69 \\
SR & 98 & 78 & 58 & 37 & 25 \\
CR & 264 & 199 & 109 & 68 & 43
\end{tabular}

Abstract 19 Figure 1 Comparison of MACE between multivessel disease.

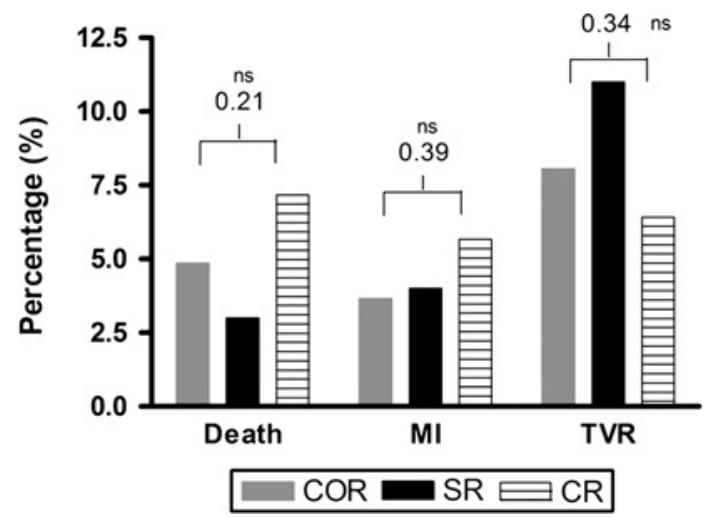

Abstract 19 Figure 2 Breakdown of MACE at 5 years.

Conclusions Culprit vessel-only angioplasty was associated with the highest rate of long-term MACE compared with multivessel treatment. Patients scheduled for staged revascularisation experienced a similar rate of MACE to patients undergoing complete simultaneous treatment of non-IRA.

\section{WHAT HAPPENS TO PLATELET FUNCTION AND VASCULAR INFLAMMMATION WHEN CLOPIDOGREL IS WITHDRAWN? INSIGHTS USING SHORT THROMBELASTOGRAPHY}

doi:10.1136/heartjnl-2011-300198.20

${ }^{1} \mathrm{~N}$ Sambu, ${ }^{2} \mathrm{H}$ Dent, ${ }^{3} \mathrm{~T}$ Warner, ${ }^{2} \mathrm{~N}$ Englyst, ${ }^{3} \mathrm{P}$ Leadbeater, ${ }^{1} \mathrm{~A}$ Hobson, ${ }^{1} \mathrm{~A}$ Calver, ${ }^{1} \mathrm{~S}$ Corbett, ${ }^{1} \mathrm{H}$ Gray, ${ }^{1} \mathrm{I}$ Simpson, ${ }^{1} \mathrm{~N}$ Curzen. ${ }^{1}$ Southampton University Hospitals NHS Trust, Southampton, UK; ${ }^{2}$ University of Southampton, School of Medicine, Southampton, UK; ${ }^{3}$ The William Harvey Research Institute, Barts and the London School of Medicine and Dentistry, London, UK

Introduction A clustering of adverse events, in particular stent thrombosis (ST) has been observed following clopidogrel cessation 1-year after drug-eluting stenting (DES), the aetiology of which is poorly understood. We investigated the effect of withdrawing clopidogrel in DES patients using a simple, rapid, reproducible nearpatient platelet function test known as short Thrombelastography (s-TEG) that has been developed and validated by this group.

Methods 33 patients on aspirin and due to stop clopidogrel at 1 year following DES were investigated. Venesection was performed at (i) 4 weeks and $24 \mathrm{~h}$ pre clopidogrel cessation (ii) $24 \mathrm{~h}, 48 \mathrm{~h}, 1,2$ and 4 weeks post clopidogrel cessation. At all time-points, platelet reactivity was determined using s-TEG and thromboxane (TX) B2, IL-6, CD40 ligand and high sensitivity CRP were measured.

Results Clopidogrel cessation produced (i) a predictable increase in ADP-induced platelet aggregation, and (ii) an unexpected and significant rise in AA-induced platelet aggregation. TXB2 was consistently suppressed confirming inhibition of COX by aspirin.
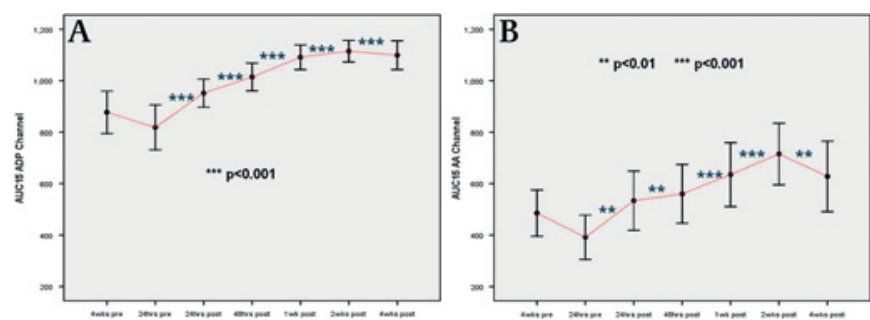

Abstract 20 Figure 1

Conclusion We have described for the first time an aspirin-independent increase in AA-induced clotting following clopidogrel withdrawal in DES patients. As well as potentially helping to explain the observed clustering of ST events early after clopidogrel withdrawal, these findings raise the question as to whether AAinduced clotting is an appropriate test of aspirin sensitivity. Our results also confirm s-TEG as a plausible candidate for near-patient platelet function testing in this field.

\section{INFLUENCE OF FRACTIONAL FLOW RESERVE MEASUREMENT ON TREATMENT-DECISIONS IN PATIENTS WITH RECENT ACUTE NON-ST ELEVATION MYOCARDIAL INFARCTION}

doi:10.1136/heartjnl-2011-300198.21

${ }^{1} \mathrm{D}$ Carrick, ${ }^{1} \mathrm{M}$ Behan, ${ }^{1} \mathrm{~F} F o o,{ }^{1} \mathrm{~J}$ Christie, ${ }^{2} \mathrm{~J}$ Norrie, ${ }^{1} \mathrm{~K}$ Oldroyd, ${ }^{1} \mathrm{C}$ Berry. ${ }^{1}$ Department of Cardiology, Golden Jubilee National Hospital, Glasgow, UK; ${ }^{2}$ Robertson Centre for Biostatistics, University of Glasgow, Glasgow, UK

Introduction Non-ST elevation acute myocardial infarction (NSTEMI) is the most common form of acute coronary syndrome and has a relatively poor prognosis. Visual interpretation of the coronary angiogram is the standard approach to guide treatment decisions in patients with recent acute NSTEMI. The aim of our study was to determine whether measurement of coronary pressure derived fractional flow reserve (FFR), compared to coronary angiography alone, might influence treatment decisions. 